\title{
Trends in the Management of Headache
}

\author{
John N. Mafi, MD', Samuel T. Edwards, MD², Nigel P. Pedersen, MB, BS ${ }^{3}$, and Bruce E. Landon, MD, \\ $\mathrm{MBA}, \mathrm{MSC}^{7,4}$
}

'Division of General Medicine and Primary Care, Department of Medicine, Beth Israel Deaconess Medical Center, Harvard Medical School, Boston, MA, USA; ${ }^{2}$ Section of General Internal Medicine, Veterans Affairs Boston Healthcare System, Boston, MA, USA; ${ }^{3}$ Department of Neurology, Beth Israel Deaconess Medical Center and Massachusetts General Hospital, Boston, MA, USA; ${ }^{4}$ Department of Health Care Policy, Harvard Medical School, Boston, MA, USA.

KEY WORDS: guidelines; utilization; ambulatory care; physician behavior; primary care.

J Gen Intern Med 30(6):711

DOI: $10.1007 /$ s11606-015-3223-8

(C) Society of General Internal Medicine 2015

7 he Authors' Reply_-We thank Dr. Solomon for his inter1 est in our study assessing national trends in headache management and for raising important questions about the usefulness of lifestyle modification counseling. As noted, we found a decline in first-line recommended lifestyle modification counseling for headache over the past decade, contrary to prominent headache guidelines. ${ }^{1}$ For instance, guidelines from the American College of Physicians suggest that physicians encourage their patients to identify and avoid specific dietary, behavioral, and environmental triggers for migraine headache. $^{2}$

While he is correct in pointing out that generic advice on improving diet and exercise habits may lack rigorous scientific evidence showing reduced headache frequency, the dietary and lifestyle counseling provided during a headache visit would likely be targeted towards specific factors that trigger headache. Moreover, we do not agree that "increased stress, dehydration, lack of sleep, sedentary lifestyle, and poor diet... have not been scientifically linked to increased migraine frequency." In fact, evidence suggests the opposite: migraine headaches are frequently triggered by stress, sleep deprivation, or dietary choice, in addition to a wide array of lifestyle and environmental factors. ${ }^{3}$

Finally, as we discuss in our paper, our measure of counseling is not limited to diet and exercise counseling. Another important component of our variable includes mental health counseling and stress management therapy, which as Dr. Solomon notes has been shown in various forms to improve headache symptoms in systematic reviews and randomized controlled trials. ${ }^{4,5}$

Corresponding Author: John N. Mafi, MD; Division of General Medicine and Primary Care, Department of Medicine, Beth Israel Deaconess Medical Center, Harvard Medical School, 330 Brookline Avenue, CO-1309, Boston, MA O2215, USA (e-mail:jmafi@bidmc.harvard.edu).

\section{REFERENCES}

1. Mafi JN, Edwards ST, Pedersen NP, Davis RB, McCarthy EP, Landon BE. Trends in the Ambulatory Management of Headache: Analysis of NAMCS and NHAMCS Data 1999-2010. J Gen Intern Med. 2015;1-8. doi:10.1007/ s11606-014-3107-3

2. Snow V, Weiss $\mathbf{K}$, Wall EM. Guidelines for the treatment and prevention of migraine headaches. Ann Intern Med. 2002;137(10):840-852.

3. Andress-Rothrock $\mathbf{D}$, King $\mathbf{W}$, Rothrock $\mathbf{J}$. An analysis of migraine triggers in a clinic-based population. Headache. 2010;50:1366-1370.

4. Goslin RE, Gray RN, McCrory DC, Penzien D, Rains J, Hasselblad V. Behavioral and physical treatments for migraine headache. Technical Review 2.2. 1999. (Prepared for the Agency for Health Care Policy and Research under contract no. 29009402025. Available from the National Technical Information Service; NTIS accession no. 127946.)

5. Holroyd KA, Cottrell CK, O'Donnell FJ, et al. Effect of preventive ( $\beta$ blocker) treatment, behavioural migraine management, or their combination on outcomes of optimised acute treatment in frequent migraine: randomised controlled trial. BMJ. 2010;341:c4871. 